\title{
INFLUÊNCIA DAS AÇÕES SOCIOAMBIENTAIS DA EMPRESA NATURA SOBRE SUAS CONSULTORAS EM SOROCABA (SP)
}

\author{
Andrea Cattaneo Hernandez ${ }^{1}$ \\ Andrea Rabinovici ${ }^{2}$
}

\begin{abstract}
Resumo: A Natura é conhecida como empresa sustentável socioambientalmente. O sistema de treinamento das consultoras para venda direta de produtos é sua principal forma de comercialização e poderia ser um campo potencial para ações de educação e sensibilização socioambiental e consumo sustentável, expandindo o potencial educador que o marketing da empresa realiza, às consultoras e aos consumidores. Esta pesquisa acompanhou reuniões de consultoras Natura da cidade de Sorocaba, SP, as entrevistou, além de fazer análise documental, à fim de avaliar se este potencial está ou não sendo utilizado e influenciando conhecimento, comportamento e atitudes de suas consultoras e consumidores, buscando compreender se, nestes processos, ocorre sensibilização referente à questões socioambientais
\end{abstract}

Palavras-chave: Educação Ambiental; Consumo Consciente; Natura Cosméticos; Consultoras; Ações Socioambientais.

${ }^{1}$ Universidade Federal de São Carlos. E-mail: Cattaneo.andrea@ymail.com.

${ }^{2}$ Universidade Federal de São Paulo. E-mail: arabinovici@unifesp.br 


\section{Introdução}

\section{Consumo consciente}

A sociedade se desenvolveu a partir da exploração dos recursos naturais. Para Padua (2004) um dos principais motivos desta exploração deuse pela visão de natureza inesgotável, perante as imensas florestas aparentemente intermináveis. Posteriormente, com o advento da revolução industrial, a poluição e a extração exacerbada tornam-se evidentes símbolos do progresso.

A manutenção de um sistema de consumo é essencial para o modelo vigente e a base da economia capitalista. A cultura passa a ser norteada por valores de mercado, os quais controlam as relações sociais, a interpretação da individualidade e a visão do direito de escolha como um poder (SLATER, 2002).

No entanto, a exploração dos recursos naturais para a perpetuação da cadeia de produção e consumo passa a evidenciar impactos ambientais consequentes de uma superexploração. A partir disso, segundo Gomes (2006, p.19) "[...] surge a preocupação com modelos sustentáveis de desenvolvimento, onde haja a conciliação entre o desenvolvimento econômico e a preservação do meio ambiente".

A mudança no cotidiano e estilo de vida dos indivíduos se torna fonte de transformação e a esperança rumo a uma sociedade ambientalmente sensibilizada (PORTILHO, 2005). No entanto, é um desafio sensibilizar profundamente uma sociedade que glorifica a satisfação imediata e 0 individualismo, prejudicando assim a base da cidadania (SANTOS, 2001).

Alterar os padrões de consumo é uma tarefa complexa. Uma Pesquisa de opinião pública, realizada conjuntamente pelos Institutos Ethos ${ }^{3}$ e Akatu $^{4}$, abordando a percepção do consumidor brasileiro, comparou os resultados obtidos entre os anos de 2006 e 2010, através dos quais se percebeu o aumento no número de consumidores considerados indiferentes aos impactos ambientais causados pelo próprio consumo, consequência provável do aumento de poder aquisitivo da população (INSTITUTO AKATU, 2010).

De acordo com Furriela (2001, p. 47) "O consumidor é ator de transformação, já que tem em suas mãos o poder de exigir um padrão de desenvolvimento socialmente justo e ambientalmente equilibrado".

\footnotetext{
3 Instituto Ethos de Empresas e Responsabilidade Social: uma instituição que busca sensibilizar e auxiliar as empresas a conduzirem seus processos de forma socialmente responsável. Disponível em: <http://www3.ethos.org.br/>. Acessado em 10/04/2012.

${ }^{4}$ Instituto Akatu pelo Consumo Consciente: que procura mobilizar o consumidor e exercer seu poder de decisão como ferramenta para a sustentabilidade. Acessado em: <http://akatu.org.br/>. Acessado em 10/04/2012.
} 
Concomitantemente começam a surgir novas formas de consumidores conscientes, comumente denominados por consumidores verdes, que levam em conta a variável ambiental no momento de suas escolhas (PORTILHO, 2005).

Para a disseminação da consciência ambiental entre os cidadãos/consumidores, faz-se necessária uma educação ambiental, que emergiu de maneira relevante na década de 1970, como um esforço para se vencer a crise ambiental (LIMA, 2005). A educação ambiental deve estimular os indivíduos a refletirem sobre suas decisões e as consequências destas para o futuro e o presente (LIMA, 2005).

Para Sachs (2002, p.31) "é necessária uma abordagem holística e interdisciplinar da questão ambiental, buscando um desenvolvimento consciente". Dessa forma a educação ambiental pode ser interpretada como precursora dessas mudanças.

\section{Estratégia corporativa sustentável}

A emergência dos problemas do século $X X$, por exemplo, aquecimento global, crises energéticas e falta de recursos hídricos destruíram a imagem de capital humano e natural como inesgotáveis e alavancaram a luta pela mudança na imagem dos processos de produção (LEMME, 2010).

Para Layrargues (2000) parte do setor empresarial assumiu realmente uma postura socioambiental engajada na década de 1980, abandonando o antagonismo entre 0 conceito de desenvolvimento e 0 de conservação ambiental. Passa-se a adotar nas empresas medidas sustentáveis, principalmente a busca pela ecoeficiência, que segundo Sachs (2002) consiste em procedimentos voltados à reciclagem, conservação de energia e água, aumento do ciclo de vida das infraestruturas e edifícios, manutenção de equipamentos e aproveitamento de resíduos. Portanto, a sustentabilidade corporativa leva as empresas rumo à modificação dos modelos de gestão para além do econômico, adentrando os planos sociais e ambientais, ou seja, o tripé da sustentabilidade (ZYLBERSZTAJN; LINS, 2010).

Segundo Zylbersztajn e Lins (2010) "Consumidores, financiadores, acionistas e investidores exigem, cada vez mais, compromissos éticos das corporações", demonstrando que existe um potencial competitivo para esse tipo de ações adotadas pelas empresas. A conscientização da sociedade e a criação de legislação que fiscaliza as atividades empresariais são propulsores de mudanças, as quais podem ser consideradas como obrigações ou ações estratégicas das empresas (LEMME, 2010).

A sustentabilidade corporativa, portanto, demanda uma gestão economicamente viável, socialmente justa e ambientalmente correta. Através da evolução na qualidade dos processos, da cadeia de suprimentos e dos produtos visando o respeito aos critérios socioambientais (LEMME, 2010). 
Além das iniciativas citadas, as empresas devem se envolver nos processos de alteração do comportamento e da cultura, primeiramente dos seus clientes internos, posteriormente da sociedade em geral. Isso ocorrerá pela promoção da educação em todos os setores das corporações, por meio de eficientes canais de comunicação (SILINGOVSCHI, 2012).

Uma empresa que estimula e adota atitudes de cuidado ao ambiente por meio de sua gestão, além de servir como um bom exemplo para a sociedade em geral, também cria um mercado consumidor fiel aos princípios socioambientais e consequentemente a ela. As empresas devem considerar os benefícios resultantes de uma conscientização socioambiental, geradora de atitudes positivas por parte de sua estrutura organizacional objetivando a sobrevivência no mercado e nos ambientes social e natural (HRDLICKA; NEIMAN, 2012).

\section{A Natura}

A Natura Cosméticos S. A. foi criada em 1969, quando contava somente com uma loja que comercializava produtos de higiene e cosméticos, em São Paulo, na qual, Antonio Luiz da Cunha Seabra atendia pessoalmente suas clientes (LEAL, 2011).

Em 2004 a empresa abre seu capital na bolsa de valores e conquista a certificação ambiental ISO 14001 (REZENDE, 1997). Segundo o Relatório Anual Natura (2011), a empresa é representada comercialmente por 1,4 milhões de consultores e consultoras distribuídos por sete países, e conta com uma receita líquida anual de $R \$ 5.591$ milhões. A empresa possui sete mil funcionários, que atuam em uma fábrica localizada em Cajamar (SP), e outra em processo de finalização em Benevides (PA). Existem cinco escritórios comerciais, em quatro estados diferentes do país. Uma sede na Argentina e um centro avançado em Paris (França) (RELATÓRIO ANUAL NATURA, 2011).

Em 2011 a empresa destinou grandes investimentos no aprimoramento da tecnologia utilizada objetivando melhorias na logística de produção e distribuição de produtos, e a redução de gases causadores do efeito estufa (RELATÓRIO ANUAL NATURA, 2011). Para concorrer no mercado nacional e internacional, a Natura conta com produtos confeccionados a partir de matérias-primas cem por cento brasileiras (RELATÓRIO ANUAL NATURA, 2011). A linha de cosméticos Ekos, produzida através de ativos naturais, é um exemplo disso, valoriza o potencial natural do Brasil também demonstra os valores sustentáveis da empresa (SILINGONSCHI, 2012). No ano de 2011 a linha Ekos foi relançada com as embalagens revisadas para a redução na emissão de gases estufa e reutilização de materiais recicláveis em sua constituição (RELATÓRIO ANUAL NATURA, 2011).

A empresa também foi a primeira a adotar o uso de refis no sentido de demonstrar sua preocupação com a questão ambiental e relacionar sua 
imagem a uma valorização dos aspectos: ambiental, econômico e social (CASTRO, 2011).

A partir de relatórios anuais, a empresa descreve de maneira voluntária suas atividades e o impacto destas no meio social, ambiental e econômico (MATOS et. al., 2007). A confecção deste segue orientações do Instituto Ethos de Empresas e Responsabilidade Social e do modelo de relatórios Global Reporting Initiative (GRI) ${ }^{5}$. Fora os relatórios anuais, os funcionários possuem acesso a um jornal de circulação interna, ao Mural Ser Natura Colaborador e no site da empresa (DINATO, 2006). Por meio de plataformas sociais a Natura oferece um canal de diálogo entre a empresa e seus clientes, funcionários, fornecedores, entre outros.

A Natura está presente, desde 2005, na lista dos relatórios do Índice de Sustentabilidade Empresarial (ISE) (BOVESPA, 2011). Esse índice une a liquidez das ações ao desempenho ambiental, social e de governança (LEMME, 2010). O ISE serve como uma referência da evidenciação e reconhecimento dos investimentos de caráter socioambiental adotados pelas empresas nele presentes (SILVA; QUELHAS, 2006). Segundo Nakahira e Medeiros (2009) esse tipo de prática por parte da empresa, reforça a confiança do consumidor em adquirir produtos produzidos de forma ambientalmente responsável.

A comercialização da empresa se dá pela venda direta, em seu Relatório Anual Natura (2011) é ressaltada a importância do modelo de venda direta na disseminação de ações e ideias engajadas na sociedade. Segundo Guimarães (2010, p.63) "De acordo com a empresa, com este modelo de negócios ela busca a criação de valor sustentável por meio da construção de relações de qualidade com a sociedade".

A empresa já considera sua gestão para sustentabilidade relevante para sua imagem perante o público consumidor, e deseja conscientizar seus colaboradores e consultoras através de projetos educacionais, almejando a construção de uma sociedade sustentável (RELATÓRIO ANUAL NATURA, 2011). Para a empresa atingir esse objetivo, esta pesquisa e seus resultados sugerem a necessidade de investimentos em projetos de educação ambiental, focados nas consultoras ${ }^{6}$ consideradas pela Natura como seus primeiros consumidores e prováveis disseminadores de ideias sustentáveis na sociedade.

\footnotetext{
${ }^{5}$ Global Reporting Initiative: é uma Organização Não Governamental, constituída em 1997, que confecciona modelos de relatórios para as empresas analisarem e divulgares seus resultados, a partir de indicadores sociais, econômicos e ambientais. Acessível em:

$<$ https://www.globalreporting.org/languages/Portuguesebrazi/Pages/default.aspx> Acessado em: 21/10/2012.

${ }^{6}$ O público entrevistado pelas pesquisadoras neste artigo é majoritariamente feminino, portanto, o gênero utilizado para se referir aos trabalhadores nos resultados será o feminino.
} 
Uma abordagem educativa de caráter socioambiental pode ser propulsora de uma sociedade mais consciente e ao mesmo tempo uma estratégia de mercado, disseminando ideias de consumo consciente e aumentando o número de consumidores interessados em empresas comprometidas com a sustentabilidade.

Desta forma os projetos educacionais, destinados às consultoras devem ter uma abordagem informal e contextualizada, para que estes sejam multiplicadores das ideias sustentáveis por meio do contato direto deste público com o mercado consumidor. A educação não formal é capaz de atingir públicos diversos, em termos de gerações, níveis socioeconômicos e culturais e amplia, por demais, o escopo daquilo que é realizado no meio escolar. Conforme o Programa Nacional de Educação Ambiental (2005, p.58) "a educação ambiental deve ter como base o pensamento crítico e inovador, em qualquer tempo ou lugar, em seu modo formal, não formal e informal, promovendo a transformação e a construção da sociedade".

Neste artigo será analisado se as ações socioambientais da empresa Natura, atingem, de fato, o cotidiano de suas consultoras, seus hábitos, reflexões acerca de questões socioambientais, sua prática enquanto vendedoras e consequentemente de seus consumidores. A empresa analisada apresenta um potencial educativo, tanto pela sua imagem quanto por sua forma de comercialização.

\section{Metodologia}

Foi realizada uma análise documental através das informações contidas nos Relatórios Anuais Natura da empresa e disponíveis em seu site, especialmente o do ano de 2011. As pesquisadoras foram autorizadas a participar das reuniões dos ciclos, para levantamento de informações fornecidas pela empresa às suas consultoras. Por fim foi confeccionado, a partir dos dados reunidos durante as reuniões, um questionário com perguntas abertas e fechadas, aplicados às consultoras. Desta forma os fenômenos sociais a serem estudados podem ser melhores compreendidos através do contexto no qual ocorrem, pois, o pesquisador é capaz de entender os fatos a partir da perspectiva das pessoas nele envolvidas, portanto a pesquisa teve uma abordagem qualitativa (GODOY, 1995).

As pesquisadoras obtiveram o contato de uma Consultora Natura Orientadora (CNO) e de uma Gerente de Vendas de Sorocaba, e foram autorizadas a participar, como observadoras, nas reuniões. Desta forma podese considerar a pesquisa um estudo de caso, como colocado por Ludke e André (1986, p.44): "O estudo de caso tem um campo de trabalho mais específico: é o estudo de um caso, sendo este sempre bem delimitado e de contornos claramente definidos".

Através dessas participações, foi possível conhecer as informações fornecidas nesses encontros, e realizar contatos com consultoras objetivando a 
aplicação de um questionário sobre o comportamento e opinião destas sobre a Natura. Foram frequentadas seis reuniões no total e três oficinas (cabelos, maquiagem e perfumaria), entre os meses de dezembro de 2011 e maio de 2012.

Após três reuniões foi formulado um questionário que visava abordar aspectos básicos como: idade, sexo, escolaridade, tempo que trabalha com a Natura, motivo de ser consultora, se exerce outras atividades remuneradas e participa ou participou de oficinas realizadas pela Natura. Posteriormente, eram realizadas perguntas que abordavam atitudes cotidianas relacionando-as com aspectos ambientais, como cuidados ao meio ambiente, opinião das consultoras em relação a atitudes da empresa e das próprias atitudes relacionadas ao cuidado com o meio ambiente por parte das mesmas. Um préteste foi feito com sete consultoras da cidade de São Paulo.

Os sujeitos da pesquisa escolhidos para a coleta de dados foram as consultoras da Natura (CNs), atuantes na cidade de Sorocaba, SP. Segundo Castro (2011) elas podem ser consideradas consumidoras da empresa, pelo fato de terem escolhido esses produtos para revenda e consequentemente representarem a Natura perante outros consumidores. A própria empresa ressalta a importância de suas consultoras/consumidoras em seu site, para que estes estabeleçam relações de qualidade com seus clientes, por meio do conhecimento da ação e dos conceitos dos produtos (NATURA, 2012).

$\mathrm{Na}$ cidade de Sorocaba existe um total de 4100 consultores divididos em 4 grupos, cada um contando com um gerente vendas, amparado por vários CNOs cujas funções, segundo o Relatório Anual Natura (2011) são: as gerentes de vendas conduzem as reuniões e auxiliam as consultoras e CNOs na resolução de possíveis problemas, já as CNOs orientam e fornecem apoio às $\mathrm{CNs}$ no desenvolvimento dos seus trabalhos.

O grupo pesquisado possui 765 consultoras cadastradas, que podem frequentar as reuniões em três períodos. Cada período de reunião conta com aproximadamente 100 consultoras, que buscam revistas de produtos e informações.

Esses encontros acontecem a cada 21 dias, momento no qual os ciclos de promoções encerram, as ofertas são renovadas e são apresentados os lançamentos. Durante as reuniões, as CNOs distribuem revistas e amostras de produtos e se caso e, caso necessário, auxiliam as CNs nos pedidos.

A gerente de Vendas realiza apresentações variadas e fornece informações sobre novas linhas, os conceitos da empresa e dos produtos e informações sobre as vendas. Ao final, são realizados sorteios de produtos.

No meio do processo desta pesquisa, constatou-se a dificuldade na devolução dos questionários, portanto a estratégia de coleta foi alterada para entrevistas individuais e presenciais, a partir do questionário. As consultoras que frequentavam as reuniões eram abordadas na entrada do local para uma 
apresentação e explicação da pesquisa e sobre a necessidade de uma entrevista. Se a proposta era aceita horário e local apropriado eram combinados. A entrevista é recomendada por Marconi e Lakatos (2011, p.80) para a coleta de dados em pesquisas descritivas e tem como definição segundo estes autores:

A entrevista é um encontro entre duas pessoas, a fim de que uma delas obtenha informações a respeito de determinado assunto, mediante a uma conversação de natureza profissional. É um procedimento utilizado na investigação social, para a coleta de dados ou para ajudar no diagnóstico ou no tratamento de um problema social.

Percebeu-se uma grande dificuldade em se efetivar as entrevistas, aproximadamente 200 abordagens foram feitas, conseguiu-se um total de 100 entrevistas agendadas, no entanto, foi alcançado um número máximo de 39 entrevistas, pois no momento em que se fazia o contato por telefone para confirmar o horário e local da entrevista, por vezes, ocorria à desistência dos entrevistados.

As entrevistas se iniciaram no mês de maio e se encerraram no final de julho de 2012. O encontro com as consultoras ocorria, geralmente, em suas próprias residências ou em seu trabalho. As entrevistas eram transcritas de maneira literal pelas pesquisadoras, já que algumas entrevistadas se mostraram constrangidas com a gravação. $O$ método apresentou a vantagem de possibilitar maior liberdade às entrevistadas e aumentar o grau de motivação para respostas mais completas. Segundo Goldenberg, essa estratégia permite maior aprofundamento nas respostas (GOLDENBERG, 1998).

Após o término das entrevistas, as respostas foram tabuladas e analisadas através de uma separação por categorias. Iniciou-se primeiramente, a confecção de um perfil geral (julho a agosto de 2012) das entrevistadas e posteriormente foi realizada (setembro de 2012 a janeiro de 2013) uma análise sobre a influência da imagem da Natura, como uma empresa preocupada com os aspectos ambientais, nas atitudes cotidianas de suas consultoras em relação ao ambiente, especialmente durante suas atividades de venda. E finalmente, realizou-se a análise da efetividade do potencial de educação ambiental pertencente à empresa entre os meses de janeiro e junho de 2012.

A pesquisa, caracterizada como estudo de caso, conseguiu uma pequena amostra de consultoras de um grupo de Sorocaba (SP), portanto, as sugestões e análises realizadas nesta pesquisa não podem ser generalizadas. A comparação feita com a pesquisa realizada com Silingovschi (2012) foi uma maneira encontrada para complementar e enriquecer a pesquisa, mesmo com a diferença entre o público alvo e número amostral entre as duas pesquisas. 


\section{Resultados}

\section{Reuniões e entrevistas: temas e amostragem}

Durante as reuniões da Natura com as consultoras os principais aspectos discutidos eram estratégias de vendas, aulas de empreendedorismo para estimular as consultoras a controlar suas finanças, informações sobre a Natura, seus programas e produtos. O principal projeto citado pelos entrevistados foi o que consiste na venda de produtos da linha Crer pra Ver.

Nas oficinas de cabelos e perfumaria, a própria gerente de vendas realizava palestras sobre a melhor forma de utilizar os produtos, por exemplo, conhecer os tipos de produtos para as características específicas das clientes. A oficina de maquiagem, contou com a apresentação de um profissional da área.

Com relação às entrevistas, embora tenham sido agendadas 100 entrevistas, o total alcançado foi de 39, devido à posterior desistência dos entrevistados.

\section{Perfil dos entrevistados}

A maioria das entrevistadas, com porcentagem igual a $92,3 \%$, é do sexo feminino e os outros $7,7 \%$ do sexo masculino. Confirmando o que relata Guimarães (2011), as vendas de produtos da Natura são realizadas em ambientes femininos de trabalho e geralmente os homens, quando exercem essa atividade, o fazem junto com suas esposas.

A faixa etária apresenta porcentagem de 35,9\%, tanto para os entrevistadas entre 31 e 40 anos, quanto para os que possuem mais de 50 anos. A faixa etária entre 41 e 50 anos é representada por $23,1 \%$ dos entrevistados. A minoria possui entre 20 e 30 anos, com uma porcentagem de $5,1 \%$.

Possui ensino médio completo $33,3 \%$ dos entrevistados, enquanto $5,1 \%$ não chegaram a finalizar o ensino médio. Dos participantes, 25,6\% possuem ensino fundamental incompleto e 10,3\% o fundamental completo. $O$ ensino superior completo é representado por $20,5 \%$ consultoras entrevistadas, entre as consultoras que possuem ensino superior incompleto ou pósgraduação a porcentagem é a mesma, igual a 2,6\%.

Quanto ao tempo de trabalho como consultoras da Natura, percebe-se que a maioria revende os produtos entre 1 e 5 anos, um total de $41 \%$ da entrevistadas. Segundo o Relatório Anual Natura, o número de consultoras praticamente dobrou nos últimos cinco anos. Enquanto apenas $12,8 \%$ são consultoras há mais de 15 anos. Entre o períodos de tempo de: menos de 1 ano, de 6 a 10 anos e de 11 a 15 anos a porcentagem é igual a 15,4\% dos entrevistados. 
A maioria das entrevistadas, $69,2 \%$, exerce outra profissão além da revenda de produtos Natura. Muitas mulheres apontaram como outra forma de trabalho a venda direta de outros produtos. Enquanto 30,8\% apenas trabalham com a revenda de produtos da empresa. Segundo Abílio (2011) o fato das consultoras, na maioria das vezes exercerem outras atividades pode se dar pela adequação das vendas aos ambientes de trabalho, no entanto, estas também podem ocorrer no círculo de amizades ou de contatos.

Mais da metade dos questionados, igual a 53,8\%, afirmou ter ido ao menos em uma das oficinas promovidas pelas empresa. Já a porcentagem de $46,2 \%$ afirmou nunca ter frequentado nenhuma oficina. A oficina mais frequentada é a de maquiagem. Outras oficinas menos frequentadas que foram mencionadas são: perfumaria, da Linha Chronos, Tratamento de Pele e Cabelos. Nenhuma oficina referente à temática socioambiental foi citada como existente.

\section{Atitudes cotidianas realizadas pelos consultoras consideradas como cuidados ao meio ambiente}

No momento desta questão, oas entrevistadas pareciam confusas, a maioria começava com a fala "reciclando" ou "separando o lixo" em tom de dúvida, como se a confirmação da pesquisadora entrevistadora fosse necessária para considerar esta ação correta. Apenas a consultora n²6 afirmou não possuir nenhum conhecimento sobre ações ambientalmente corretas, e consequentemente não praticar nenhuma.

A principal atitude indicada por $30,8 \%$ das consultoras é a separação de resíduos com destinação a reciclagem. Enquanto 48,7\% além de separarem os resíduos realizam outras atitudes, 17,9\% afirmaram realizar atitudes isoladas diferentes da separação de resíduos. As diferentes ações mencionadas e colocadas aqui em ordem crescente, foram: economia de água e energia (12 respostas); cuidado em não sujar vias públicas (2 respostas); a oferta de refis para os clientes (2 respostas); uso de sacolas retornáveis ( 1 resposta); descarte correto de pilhas e bateria (1 resposta); o fato de trabalhar com a Natura (1 resposta); o esforço de evitar o uso de automóveis (1 resposta) e doar objetos velhos (1 resposta).

\section{Mudança de postura em relação ao ambiente depois que começou a trabalhar com a Natura}

Notaram mudanças em suas atitudes cotidianas 46,2\% das entrevistadas. Apenas duas consultoras, não souberam explicar quais mudanças aconteceram. Seis respostas ressaltaram o maior cuidado com os resíduos sólidos.

Trabalhar para a empresa não influenciou 53,8\% das entrevistadas em suas atitudes de cuidado ao meio ambiente. Muitas asseguraram que já 
praticavam atitudes ambientalmente responsáveis, como a separação de resíduos, antes de trabalharem com a Natura.

\section{Preocupação com os aspectos ambientais no momento da venda}

Das questionadas, $79,5 \%$ afirmaram possuir preocupação com os aspectos ambientais no momento da venda, entre estes, a maioria das respostas citaram os refis como a forma de contribuição com o meio ambiente. Duas consultoras afirmaram que pedem as embalagens de volta para enviá-las para reciclagem ou para a própria Natura.

Responderam negativamente a essa questão 20,5\%. Dois consultores afirmaram que não oferecem o refil com frequência, três consultoras não souberam explicar a resposta negativa. Uma consultora alegou nunca considerar a variável ambiental no momento das vendas.

\section{Atitudes que tornam a Natura uma empresa sustentável}

Mencionaram apenas os refis como suficientes para uma imagem ambientalmente correta $15,4 \%$ das entrevistadas, enquanto $10,8 \%$ associaram os refis com outras ações. Consideraram as embalagens recicláveis responsáveis por esse mérito da empresa $12,8 \%$, e outras cinco respostas relacionaram as embalagens com outros aspectos. Outros aspectos citados foram: os projetos e programas sociais; projetos e programas de preservação do ambiente natural; ações relacionadas com a empresa e sua produção.

Apenas uma consultora não considera a Natura uma empresa sustentável, enquanto outra alegou desconhecimento sobre essa questão.

\section{Você utiliza informação sobre o meio ambiente como estratégia de venda?}

O discurso ambiental no momento das vendas não é utilizado por $64,1 \%$ das entrevistadas, entre as justificativas muitos afirmam que ninguém se interessa ou muitos clientes já conhecem as ações da Natura. Para uma consultora $\left(n^{\circ} 15\right)$ os produtos são vendidos com muita facilidade, sem nessidade de nenhuma informação. $E$ para a consultora $n^{\circ} 35$ essas estratégia não tem poder de convencimento.

$35,9 \%$ das consultoras consideram que informações sobre os refis vendem mais, pois, os clientes são convencidos a comprar determinado produto, no entanto, isso pode ocorrer pelo preço e não (apenas) pela questão ambiental. Os produtos sazonais também são utilizados como estratégias, afinal saem dos catálogos de tempos em tempos. 


\section{Já encontrou consumidores interessados em informações sobre os cuidados ao meio ambiente realizados pela Natura}

Um total de $71,8 \%$ das entrevistadas afirmaram nunca ter encontrado clientes interessados em atitudes da Natura relacionadas ao cuidado com 0 meio ambiente, doze não souberam explicar o fato. Seis explicaram que as pessoas não se interessam por isso, geralmente só querem conhecer os benefícios estéticos do produto. Já $28,2 \%$ afirmam já terem encontrado consumidores interessados, entre elas seis não souberam explicar de que forma o interesse se manifestou.

\section{Suas vendas se alteram ao mencionar os cuidados ao meio ambiente?}

Uma porcentagem igual a $38,5 \%$ afirmou que mencionar os cuidados da Natura ao meio ambiente não altera em nada sua vendas. Seis consultoras não conseguiram explicar essa afirmação. Duas consultoras e um consultor disseram que não auxilia nas vendas, mas talvez colabore com a conscientização dos clientes.

Já 15,4\% afirmaram que talvez auxilie na venda de refis e produtos de época, mas não têm certeza se o atrativo é a questão ambiental ou o preço acessível dos refis e a qualidade exótica dos produtos de época. Enquanto $46,1 \%$ acreditam que o discurso abordando o cuidado da Natura com o meio ambiente auxilia nas vendas, desses, cinco consultoras não souberam explicar de que maneira, seis consideram que provavelmente aumenta a saída de produtos com refil. A estratégia de produtos sazonais surge novamente em uma das afirmações. Quatro consultoras consideram que seus consumidores são conscientes e avaliam as ações da Natura para comprar.

\section{Informações mais eficientes no momento da venda}

A maioria de $87,2 \%$ das estrevistadas afirmaram que os principais aspectos de convencimento no momento das vendas são a qualidade e os efeitos dos produtos. Apenas 12,8\% mencionaram o meio ambiente como informação eficiente de venda.

\section{Discussão}

Considerando-se que a Natura está listada no Índice de Sustentabilidade Empresarial (ISE), o que indica que suas ações se relacionam com a sustentabilidade, é importante analisar se essas ações se estendem às consultoras e consequentemente em seu mercado consumidor. O principal impacto poderia ser a mudança nos padrões de consumo, com ações mais conscientes, por meio da influência de informações fornecidas pelas consultoras a seus clientes. 
Ao analisar as respostas, constata-se que grande parte das informações, consideradas como de cuidado ou preocupação com o meio ambiente, se relacionam com formas mais eficientes de venda.

No cotidiano, 30,8\% das consultoras afirmaram que contribuem com o cuidado ao meio ambiente principalmente, separando os resíduos sólidos. Enquanto 48,7\% mencionaram outras ações além da separação de resíduos, a principal delas foi à economia de água e luz. Apenas uma consultora considerou seu trabalho com a Natura como contribuição, um reconhecimento de que a escolha por uma empresa com valores ambientais é uma forma positiva de agir. A empresa não influenciou uma mudança de postura em relação ao ambiente para $53,8 \%$ das entrevistadas, o que demonstra que as ações adotadas pela empresa não causam tanto impacto e provavelmente não estão sendo divulgadas por estas entrevistadas.

Na maioria das respostas a separação de resíduos é uma das principais atitudes apontadas como preocupação ambiental. Entretanto, conforme Layrargues (2002), nos ambientes de ensino e na sociedade, este assunto é tratado de forma simplista e reduzida, pois apenas é ressaltada a diferença no momento do descarte de resíduos, ao invés de uma análise profunda dos hábitos de consumo e na redução da produção de resíduos.

Na pesquisa de Silingovschi (2012), realizada com CNOs do Estado de São Paulo, em uma questão sobre o comportamento cotidiano influenciado pela sustentabilidade, a autora verificou que $80 \%$ das respostas apontaram a separação de resíduos como atitude sustentável, enquanto, outras ações de consumo consciente apresentaram porcentagens de $41 \%$.

As CNOs, além de comercializarem produtos Natura, orientam as atividades das consultoras. É importante ressaltar a importância dessas para a disseminação de ideias e atitudes sustentáveis entre as consultoras. Conforme a pesquisa de Silingovschi (2012) uma porcentagem de 17\% de CNOs entrevistadas não estimula os consultores a conversar sobre ações sustentáveis da empresa com seus clientes. Por outro lado $22 \%$ reconhecem a importância de transmitir as práticas da empresa aos seus clientes, objetivando melhorar o ambiente e tornar a marca uma prioridade (SILINGOVSCHI, 2012).

No momento da venda, $79,5 \%$ das consultoras consideram vender 0 refil, uma maneira de demonstrar a preocupação ambiental. Este também foi citado como a principal atitude que torna a Natura uma empresa sustentável em $25,6 \%$ das respostas. Segundo Castro (2011) a empresa foi pioneira na utilização destes, os quais apresentam menor preço e talvez por isso, sejam mais sedutores.

A utilização do discurso ambiental como estratégia de venda, é utilizada por $35,9 \%$ das entrevistadas. Novamente os refis reaparecem como principal resposta, provavelmente por ser uma possibilidade economicamente atrativa ao invés de uma preocupação ambiental. Quanto ao restante de $64,1 \%$ de 
respostas negativas cabe ressaltar que uma consultora afirma que os produtos praticamente se vendem sozinhos, enquanto outra afirma que as pessoas já conhecem as atividades da Natura.

O fato acima, consequentemente, está relacionado à pergunta sobre a alteração das vendas quando os aspectos ambientais são mencionados por parte das consultoras, na qual, $46,1 \%$ das respostas afirmam que sim, aumenta a venda de refis e provavelmente de produtos sazonais. Em contrapartida, em algumas falas percebe-se que o convencimento não se dá pela questão ambiental e sim, novamente pelo preço e pela especificidade de determinados produtos. A combinação entre embalagens feitas de forma sustentável e ativos naturais amazônicos, como ocorre principalmente na linha Ekos, praticamente não foi mencionada com clareza pelas entrevistadas. Já entre as que não acreditam em um discurso ambiental, apenas três entrevistadas mecionaram a sensibilização e/ou conscientização como resultado.

Os produtos sazonais mencionados remetem principalmente a linha Natura Ekos, que utiliza ativos naturais extraídos com técnicas sustentáveis e projetos de desenvolvimento das comunidades que extraem estas matérias primas (RELATÓRIO ANUAL NATURA, 2010). Segundo o Relatório Anual Natura (2002, p.13) "A linha Natura Ekos firma-se como principal meio de valorização da flora brasileira", é a menina dos olhos da empresa perante ao mercado externo (DINATO, 2006) e possui um potencial para discussão de técnicas sustentáveis adentrando o tripé econômico, social e ambiental.

De acordo com a pesquisa de Silingovschi (2012) $77 \%$ das CNOs entrevistadas buscam discutir sustentabilidade com as consultoras que auxiliam, principalmente através da linha Natura Ekos e do projeto Crer para Ver, sendo que o refil também está presente nas respostas.

Segundo a pesquisa, 94,9\% das entrevistadas afirmaram que a Natura, no caso a gerente de vendas, oferece diversas informações sobre os produtos durante as reuniões. A pesquisadora constatou esse fato, diversos vídeos e explicações sobre os ingredientes dos produtos, os conceitos das linhas e as possíveis indicações são passados durante os encontros.

Quanto ao índice de consumidores interessados em ações ambientais realizadas pela Natura Cosméticos S.A., 71,8\% das consultoras afirmam nunca terem sido questionadas por consumidores sobre aspectos ambientais relacionados à empresa. As informações mais relevantes para $87,2 \%$ dos consumidores são, principalmente, os benefícios e as qualidades do produto (cor, textura e cheiro). Provavelmente a falta de interesse dos consumidores ocorre pela escassa informação passada pelas consultoras. Estes, por sua vez, também desconhecem muitas ações da empresa.

A pesquisa de Silingovschi (2012) conclui que as CNOs entrevistadas não dominam claramente os conceitos de sustentabilidade. No entanto as mesmas consideram relevante que as consultoras possuam conhecimento 
sobre estes conceitos, visando o aumento das vendas. Como geralmente são encarregadas pela orientação de um grupo de consultoras, o processo de conscientização e disseminação de ideias sustentáveis e de consumo consciente poderia começar pelos grupos de CNOs. As CNOs, pelo contato direto com as consultoras poderiam ser as primeiras educadoras ambientais.

Outra possibilidade da empresa é o desenvolvimento da educação informal, por meio de oficinas ou reuniões diferenciadas, com a valorização dos ambientes naturais, utilizando-se recursos como: depoimentos em vídeo de pessoas das comunidades envolvidas na retirada dos ativos naturais; contato direto com os produtos in natura naturais secos ou tratados; palestras sobre atitudes sustentáveis como a logística reversa; discussões sobre atitudes diárias relacionadas ao ambiente para troca de experiência; incentivo massivo a conversas com os clientes sobre as atitudes sustentáveis da empresa.

A empresa possui uma grande capilaridade no mercado, já que apresenta um exército de mais de um milhão de consultoras, as quais revendem seus produtos por meio de relações diferenciadas, na qual a consultora conhece ou é amigo de seu cliente. No entanto, apesar da empresa e, principalmente, seus criadores serem pioneiros em ideias sustentáveis, através da tecnologia implementada na em toda cadeia produtiva da empresa, as intenções nem sempre conseguem atingir efetivamente as ações.

Os relatórios anuais não possuem uma linguagem acessível, nem ampla divulgação entre as consultoras. Para uma maior abrangência da conscientização, informações necessárias para 0 aprimoramento das consultoras podem estar presentes em folhetos ou slides, que expliquem 0 ciclo de vida dos produtos e a consequência de ações individuais no ambiente, como meio de levar ao entendimento da visão sistêmica (PANAROTTO, 2005) dos processos de produção, da utilização e do descarte dos produtos.

A empresa provavelmente, já conta com diversos materiais e estratégias propostos aqui, entretanto, no período de reuniões frequentadas pelas pesquisadoras, estes aspectos foram apenas comentados durante as reuniões. Faz-se necessária, portanto, a incorporação da educação ambiental por parte dos consultores como uma estratégia em longo prazo visando a captação de novos clientes e a fidelidade dos antigos. Não foi encontrado pela pesquisadora um trabalho, realizado pela empresa, exclusivo de educação ambiental voltado às consultoras. Fato que demonstra uma incoerência entre o discurso da empresa e a efetividade de suas ações de cunho socioambiental na etapa final de seu processo, a comercialização.

A dificuldade é perceptível, a necessidade da empresa de comercializar, e principalmente, treinar os seus comerciantes, tarefa de difícil alcance em vista do número elevado e da diversidade do público revendedor. 


\section{Reflexões finais}

A empresa Natura Cosméticos S.A., seus valores e visão de mundo são importantes para esta pesquisa por ser uma empresa emblemática de um modelo de sustentabilidade no setor produtivo e, reconhecendo-se o poder do setor empresarial na dinâmica social do século XXI. Este estudo se propôs a analisar se o discurso, embasado muitas vezes nas ações da empresa, influencia as falas e ações daqueles que comercializam os produtos. Afinal a empresa apresenta potencial educacional, já que afirma adotar práticas responsáveis em relação à sociedade e ao ambiente e por trabalhar de forma capilarizada, com muitas consultoras, as quais poderiam ser educadoras, de forma exponencial, de seus clientes.

A partir das respostas, a preocupação com o ambiente por parte das consultoras tanto nas atitudes cotidianas quanto no momento da venda, se resume à separação dos resíduos sólidos e a economia de água e luz. Na comercialização dos produtos, a questão ambiental foi relacionada constantemente aos refis e produtos sazonais.

As atitudes cotidianas citadas muitas vezes envolvem economia financeira ao invés de uma real sensibilização dos impactos dessas atitudes individuais no ambiente. No momento da venda as variáveis ambientais vêm sempre acompanhadas do incentivo ao consumo, a partir de um discurso de preservação e valorização dos produtos nacionais, enquanto se estimula a venda. Não se nota nesse grupo de entrevistadas uma preocupação real com a conscientização de seus clientes e, por conseguinte uma preocupação da Natura em estimular tal possibilidade. Não há menção à possibilidade de se ter um consumo sustentável, nem conceitualmente, nem na prática.

Um desestímulo a uma abordagem ambientalmente engajada pode estar relacionado à pequena porcentagem de clientes interessados nas ações socioambientais da empresa. Se a principal preocupação dos consumidores é o benefício e as características físicas dos produtos e seu preço, as pessoas responsáveis pelas vendas não percebem a necessidade de mencionar aspectos ambientais, já que o objetivo principal é vender e não educar, como práticas separadas e que não podem dialogar. Consequentemente o interesse e a busca sobre informações de cuidado ao meio ambiente podem ser negligenciados.

Apesar de a comercialização ser essencial para a Natura e suas consultoras, a manutenção da imagem de empresa sustentável é importante, especialmente pelo diferencial competitivo no mercado. Esses valores defendidos e estimulados por projetos e ações podem atingir também a venda direta de maneira profunda, através de estratégias educacionais voltadas para o ambiente.

As pessoas que comercializam os produtos são potenciais educadores ambientais, pela facilidade as informações disponíveis da Natura e intenso 
contato com público. Mas as consultoras também necessitam ter acesso a táticas educacionais diferenciadas, que despertem 0 interesse dessas trabalhadoras para ocorrer a sensibilização e a internalização de novos conceitos e consequentemente atitudes diferenciadas, como por exemplo, a preocupação socioambiental durante as vendas, a prática do consumo consciente como opção de fidelização de um cliente preocupado ou engajado com tais ideias e práticas.

Embora resultados alcançados em outra pesquisa realizada com as CNOs do Estado de São Paulo apontarem a mídia como meio eficiente da realização de educação ambiental entre $\mathrm{CNs}$, o desenvolvimento de oficinas e reuniões explorariam de maneira prática temas de EA, além de proporcionarem a troca de opiniões e experiências entre CNs, CNOs e Gerentes de Vendas.

Reuniões de frequência obrigatória, voltadas para assuntos socioambientais ou uma maior abordagem de conteúdos relacionados ao meio ambiente poderão incitar o crescimento de uma consciência e sensibilização ambiental, assim como um sistema simples de recompensas e pontuações por meio de ações adotadas por consultoras. Durante as reuniões ou oficinas, poderiam ser empregadas estratégias mais dinâmicas, que envolvam imagens e fatores que influenciem tanto o lado emocional quanto racional, e consequentemente, a sensibilização e a conscientização socioambiental.

A empresa pode realizar a valorização de suas consultoras realizando, além de oficinas voltadas a sensibilização ambiental, um compilado de relatos com personagens reais, consultoras que sentem orgulho de fazer parte de uma empresa pioneira em pensar sustentavelmente. Cada grupo de consultoras de determinada cidade escolheria uma consultora com atitudes compatíveis com o discurso da empresa, por exemplo, uma líder comunitária ou a dona de uma cooperativa de reciclagem, e colheria relatos de pessoas que admirem este indivíduo e ideia. Esse tipo de estratégia seria uma forma simples, local e efetiva de alavancar a autoestima destes trabalhadores.

A empresa Natura Cosméticos S.A., tal como qualquer outra, depende integralmente da comercialização de seus produtos para sua existência no mercado. As consultoras têm como, sua maior estratégia de vendas, também a comercialização massiva de produtos. Criando-se uma rede de EA que incite a divulgação e a valorização de ações socioambientais da empresa, o número de consumidores interessados em produtos Natura também poderá aumentar.

Um maior investimento em uma mídia mais massiva, que estimule a mudança em pequenas atitudes cotidianas de seus consumidores, que chame a responsabilidade de cuidados ao meio ambiente para seus consultores pode ser uma das forças propulsora da conscientização de quem vende e de quem compra os produtos da Natura Cosméticos S.A.. A empresa só tem a ganhar com a criação de um mercado consumidor interessado em suas ações socioambientais, a partir de um cliente que também queira fazer parte do processo de mudança para uma sociedade sustentável. 
No entanto, considerando-se que a questão do consumo consciente envolve também 0 abandono das necessidades criadas pela publicidade e a mudança nos padrões de consumo, sempre permanecerá a contradição relativa ao consumo sustentável e redução do consumo. Fator que ocorre especialmente com itens relacionados ao consumo de luxo ou supérfluos, tal como podem ser considerados os cosméticos, um dos segmentos mais importantes da economia mundial, sendo o Brasil uma das lideranças em termos de produção ${ }^{7}$. Mesmo com as empresas assumindo atitudes e valores socioambientais, trata-se de produtos que não são de primeira necessidade, cujos investimentos poderiam resolver graves problemas mundiais, como, por exemplo, alfabetizar, erradicar a fome, cuidar da saúde reprodutiva das mulheres, entre outros, como mostra a Tabela a seguir, com dados de 2003, mas que serve como fonte de reflexão:

Tabela 1-6. Gasto Anual em Itens de Luxo Comparado com os Recursos Necessários para o Atendimento de Necessidades Básicas Selecionadas

\begin{tabular}{|c|c|c|c|}
\hline País & $\begin{array}{l}\text { Gasto } \\
\text { Anual }\end{array}$ & Objetivo Social ou Econômico & $\begin{array}{l}\text { Investimento Extra } \\
\text { Anual Necessário para } \\
\text { Atingir o Objetivo }\end{array}$ \\
\hline Cosméticos & US\$ 18 bilhões & Saúde reprodutiva para todas as mulheres & US\$ 12 bilhões \\
\hline $\begin{array}{l}\text { Ração de animais de } \\
\text { estimação na Europa e } \\
\text { Estados Unidos }\end{array}$ & US\$ 17 bilhões & Erradicação da fome e má-nutrição & US\$ 19 bilhões \\
\hline Perfumes & USS 15 bilhões & Alfabetização universal & USS 5 bilhões \\
\hline Cruzeiros marítimos & US\$ 14 bilhões & Água potável para todos & US\$ 10 bilhões \\
\hline Sorvetes na Europa & USS 11 bilhões & Vacinação de todas as crianças & USS 1,3 bilhão \\
\hline
\end{tabular}

Fonte: Estado do Mundo, 2004: estado do consumo e o consumo sustentável/Worldwatch Institute, 2004. Acessível em: <http://www.worldwatch.org.br/em2004 eiglesias.htm>.

Esta Tabela tem como fonte o artigo: The Beauty Business: Pots of Promises $(2003)^{8}$ que aborda de forma crítica o uso, consumo, publicidade e produção de cosméticos na contemporaneidade e suas consequências econômicas, sociais, morais e éticas. Estas questões precisam ser consideradas por todos os envolvidos, especialmente pelos que produzem, comercializam e consomem cosméticos. A educação ambiental pode ajudar a colocar tais questões no centro do debate, incluindo a vertente ambiental e, assim, possibilitar a sensibilização e a conscientização para o ambiente e o

\footnotetext{
7 De acordo com a Associação Brasileira da Indústria de Higiene Pessoal Perfumaria e Cosméticos (2012): "Em relação ao mercado mundial de Higiene Pessoal, Perfumaria e Cosméticos, conforme dados do Euromonitor de 2011, o Brasil ocupa a terceira posição. É o primeiro mercado em perfumaria e desodorantes; segundo mercado em produtos para cabelos, produtos para higiene oral, masculinos, infantil, proteção solar; terceiro em produtos cosmético cores; quarto em depilatórios; quinto em pele". Acessível em: <http://www.abihpec.org.br/wpcontent/uploads/2012/04/Panorama-do-setor-2011-2012-04-FEV-2013.pdf>. Acessado em $26 / 05 / 2013$

${ }^{8}$ http://www.economist.com/node/1795852. Acessado em 25/05/2013
} 
consumo, de forma que o que pode ser considerado cosmético e supérfluo possa entrar na agenda de algo importante para o amadurecimento de parcela da população e que esta parcela possa irradiar tal debate, postura e ética, para as demais atividades ligadas ao consumo.

\section{Referências}

ABÍLIO, L.C. O make up do trabalho: Uma empresa e um milhão de revendedoras de cosméticos. 2011. 308f. Tese (Doutorado em Ciências Sociais). IFCH/ UNICAMP. Campinas, 2011.

BOVESPA, Bolsa de Valores de São Paulo. Índice de Sustentabilidade Empresarial. São Paulo, BOVESPA, 2011. Disponível em: $<$ http://www.bmfbovespa.com.br/indices/Resumolndice.aspx?Indice=ISE\&idiom $\underline{a=p t-b r}>$ Acesso em: 02/11/2012.

BRASIL. Programa Nacional de Educação Ambiental - ProNEA. Brasília, 2005. Disponível em: <http://www.mma.gov.br/educacao-ambiental/politica-deeducacao-ambiental/programa-nacional-de-educacao-ambiental> Acesso em 21/03/2012.

CASTRO, A.E.I. Investimentos Socioambientais para posicionamento de marca: Um estudo de caso sobre a imagem organizacional. 2011. $122 \mathrm{f}$. Dissertação (Mestrado em Administração) - Programa de Pós-Graduação em Administração, Universidade Federal de Santa Maria, Santa Maria, RS. 2011

DIEGUES, A.C. Desenvolvimento Sustentável ou Sociedades Sustentáveis - da crítica dos modelos aos novos paradigmas. São Paulo em Perspectiva, n. 6, v. 2, pp. 22 - 29, 1992.

DINATO, M. R. Produção e consumo sustentáveis: o caso Natura Cosméticos. Porto Alegre: UFRGS, 2006. 138 f. Dissertação (Doutorado em Administração) - Programa de Pós-Graduação em Administração de Empresas, Departamento de Administração, Universidade Federal do Rio Grande do Sul, Porto Alegre, 2006.

FURRIELA, R. B. Educação para o Consumo Sustentável. In: Ministério da Educação. Secretaria de Educação Fundamental Depto de Política da Educação Fundamental. Ciclo de Palestras sobre Meio Ambiente. Brasília. 2001. pp. $47-55$.

GRI, Global Reporting Initiative. Disponível em: $<$ https://www.globalreporting.org/languages/Portuguesebrazil/Pages/default.asp x> Acesso em: 15/05/ 2012. 
GODOY, A.S. Pesquisa qualitativa: tipos fundamentais. Revista de administração de empresas, São Paulo, v. 35, n. 2, mar./abr. 1995. pp.2029.

GOLENBERG, M. A arte de pesquisar: como fazer pesquisa qualitativa em ciências sociais. $2^{\mathrm{a}}$ ed. Rio de Janeiro (RJ): Record, 1998.

GOMES, D.V. Educação para o consumo ético e sustentável. Rev. Eletrônica. Mest. Educ. Ambient., Porto Alegre, v.16, pp.18-31, jan/jun 2006.

GUIMARÃES, T. J. Instituições e Empresas no Processo de Geração de Inovações: Um estudo de caso da Natura. Dezembro de 2010. 112p. Dissertação (Mestrado em Políticas Públicas). Programa de Pós-Graduação em Políticas Públicas, Estratégias e Desenvolvimento. Universidade Federal do Rio de Janeiro. Rio de Janeiro. Dezembro de 2010.

HRDLICKA, H.A.; NEIMAN, Z. Responsabilidade socioambiental e o Incremento nas Exportações Brasileiras: Um paradoxo. Oñati Série Sócio-Jurídico, vol. 2, No. 3, 2012.

INSTITUTO ALANA. Web site. 2012. Disponível em: <http://alana.org.br/> Acesso em: 10/04/2012.

INSTITUTO BRASILEIRO DE DEFESA DO CONSUMIDOR. Brasília: Consumers International/MMA/MEC/IDEC, 2012.

INSTITUTO AKATU. O consumidor brasileiro e a sustentabilidade: Atitudes e Comportamentos frente ao Consumo Consciente, Percepções e Expectativas sobre a RSE. Realização Instituto Akatu e Instituto Ethos.

INSTITUTO NATURA. Relatório Instituto Natura 2011. Disponível em: $<$ http://www.institutonatura.org.br/institucional/relatorio-anual-do-institutonatura-2011/> Acesso em: 20/10/2012.

INSTITUTO ETHOS DE EMPRESAS E RESPONSABILIDADE SOCIAL. 2012. Disponível em: $<$ http://www1.ethos.org.br/EthosWeb/pt/29/o que e rse/o que e rse.aspx>. Acesso em: 15/03/ 2012.

LAYRARGUES, P. P. Sistemas de gerenciamento ambiental, tecnologia limpa e consumidor verde: a delicada relação empresa-meio ambiente no ecocapitalismo. Rev. adm. empres., São Paulo, v. 40, n. 2, Jun. 2000. 
LAYRARGUES, P.P. O cinismo da reciclagem: o significado ideológico da reciclagem de lata de alumínio e suas implicações para a educação ambiental. In: LOUREIRO, C.F.B, LAYRARGUES, P.P.; CASTRO, R. S. de. (Orgs.) Educação ambiental: repensando o espaço da cidadania. 2. ed. São Paulo: Cortez, 2002.

LEAL, G. P. Liderança com Eros à flor da pele. In: VOLTOLINO, R. Conversas com líderes sustentáveis. Editora Senac, 2011, pp.129-146.

LEMME, C.F. O valor gerado pela sustentabilidade corporativa. In: ZYLBERSZTAJN, D.; LINS, C. Sustentabilidade e geração de valor: a transição para o século XXI. Rio de Janeiro: Elsevier, 2010, pp. 37- 63.

LIMA, G.F.C. Crise ambiental, educação e cidadania: os desafios da sustentabilidade emancipatória. In: LOUREIRO, C.F.B.; LAYRARGUES, P.P.;CASTRO, R.S. (Org.). Educação ambiental: repensando o espaço da cidadania. São Paulo: Cortez, 2002. pp.. 109-141.

LUDKE, M.; ANDRÉ, M.E.D. Pesquisa em educação: abordagens qualitativas. São Paulo: Editora Pedagógica e Universitária, 1986.

MATTOS, B. et. al. A Evidenciação Voluntária do Capital Intelectual de Natureza Social e Ambiental da Empresa Natura Cosméticos S.A. no Período de 2003 a 2008. Anais do $3^{\circ}$ Congresso UFSC de Iniciação Científica em Contabilidade ano 2009.

MARCONI, M. A.; LAKATOS, E. M. Técnicas de Pesquisa: planejamento e execução de pesquisas, amostragens e técnicas de pesquisa, elaboração, análise e interpretação de dados. 7. ed. São Paulo: Atlas, 2011.

NAKAHIRA, E; MEDEIROS, G.A. Rotulagem Ambiental: O caso do Setor do comércio. Engenharia Ambiental, v. 6, n. 2, pp. 544-563, mai /ago, 2009.

NATURA. A empresa. Disponível em: <http://scf.natura.net/SobreANatura/>. Acesso em:19/04/ 2012.

NATURA. Relatório Anual Natura 2011, 117p. Disponível em:<http://scf.natura.net/relatorios/2011/ PDF/PORT PDF NAVEGAVEL.pdf >. Acesso em: 28/03/ 2012.

PADUA J.A. A ocupação do território brasileiro e a conservação dos recursos naturais. In: MILANO, M.; TAKAHASHI, L.; NUNES, M. (Org.) Unidades de Conservação: atualidades e tendências. Curitiba, 2004, pp.12-19. 
PANAROTTO, C. O meio ambiente e o consumo sustentável: alguns hábitos que podem fazer a diferença. Revista das relações de consumo. Caxias do Sul: 2008.

PORTILHO, F. Consumo sustentável: limites e possibilidades de ambientalização e politização das práticas de consumo. Cad. EBAPE. BR, Rio de Janeiro, v. 3, n. 3, 2005.

REZENDE, Y. Natura cosméticos: Quando é virtuoso ser virtual. Ci. Inf., Brasília, v. 26, n. 2, maio de 1997.

SACHS, I. Caminhos para um desenvolvimento sustentável. Rio de Janeiro, Garamond, 2002. $95 \mathrm{p}$.

SANTOS, M. Por uma outra globalização: do pensamento único à consciência universal. Rio de Janeiro; São Paulo: Record, 2000.

SILINGOSCHI, T. M. Assimilação de valores que contribuem para a sustentabilidade pela ótica das Consultoras Orientadoras da Natura. 2012. 127f. Dissertação de Mestrado. Escola Superior de Conservação Ambiental e Sustentabilidade- ESCAS. Nazaré Paulista, SP. 2012.

SILVA L.S.; QUELHAS O.L.G. Sustentabilidade empresarial e o impacto no custo de capital próprio das empresas de capital aberto. Gestão \& Produção, São Carlos, v. 13, n. 3, set./dez. 2006.

SLATER, D. Cultura do consumo \& modernidade. São Paulo: Nobel, 2002.

ZYLBERSZTAJN, D.; LINS, C. Sustentabilidade e geração de valor: a transição para o século XXI. Rio de Janeiro: Elsevier, 2010. $207 f$. 